Supplement of The Cryosphere, 14, 1633-1650, 2020

https://doi.org/10.5194/tc-14-1633-2020-supplement

(C) Author(s) 2020. This work is distributed under

the Creative Commons Attribution 4.0 License.

(c) (1)

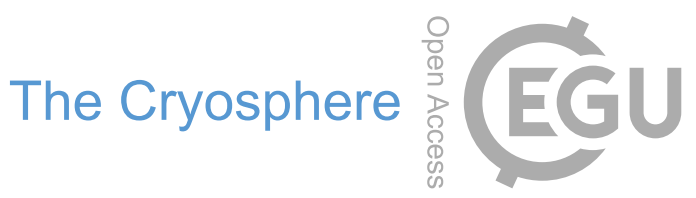

Supplement of

\title{
InSAR time series analysis of seasonal surface displacement dynamics on the Tibetan Plateau
}

Eike Reinosch et al.

Correspondence to: Eike Reinosch (e.reinosch@tu-braunschweig.de)

The copyright of individual parts of the supplement might differ from the CC BY 4.0 License. 

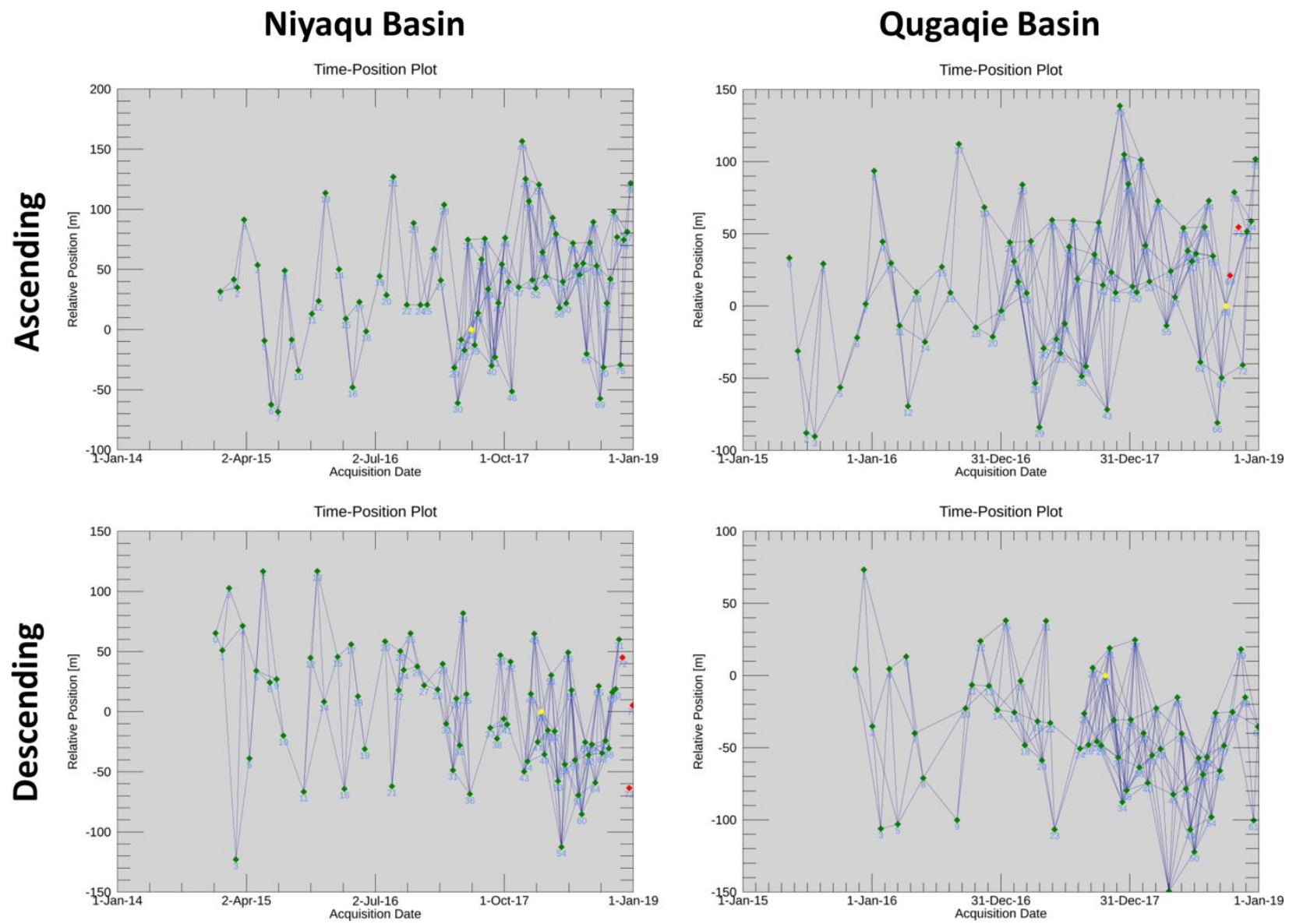

S1: SBAS connection graphs of ascending and descending data sets for both study areas. Data acquisitions shown in red were discarded due to poor coherence of interferograms. The acquisitions shown in yellow were used as master scenes for co-registration. 


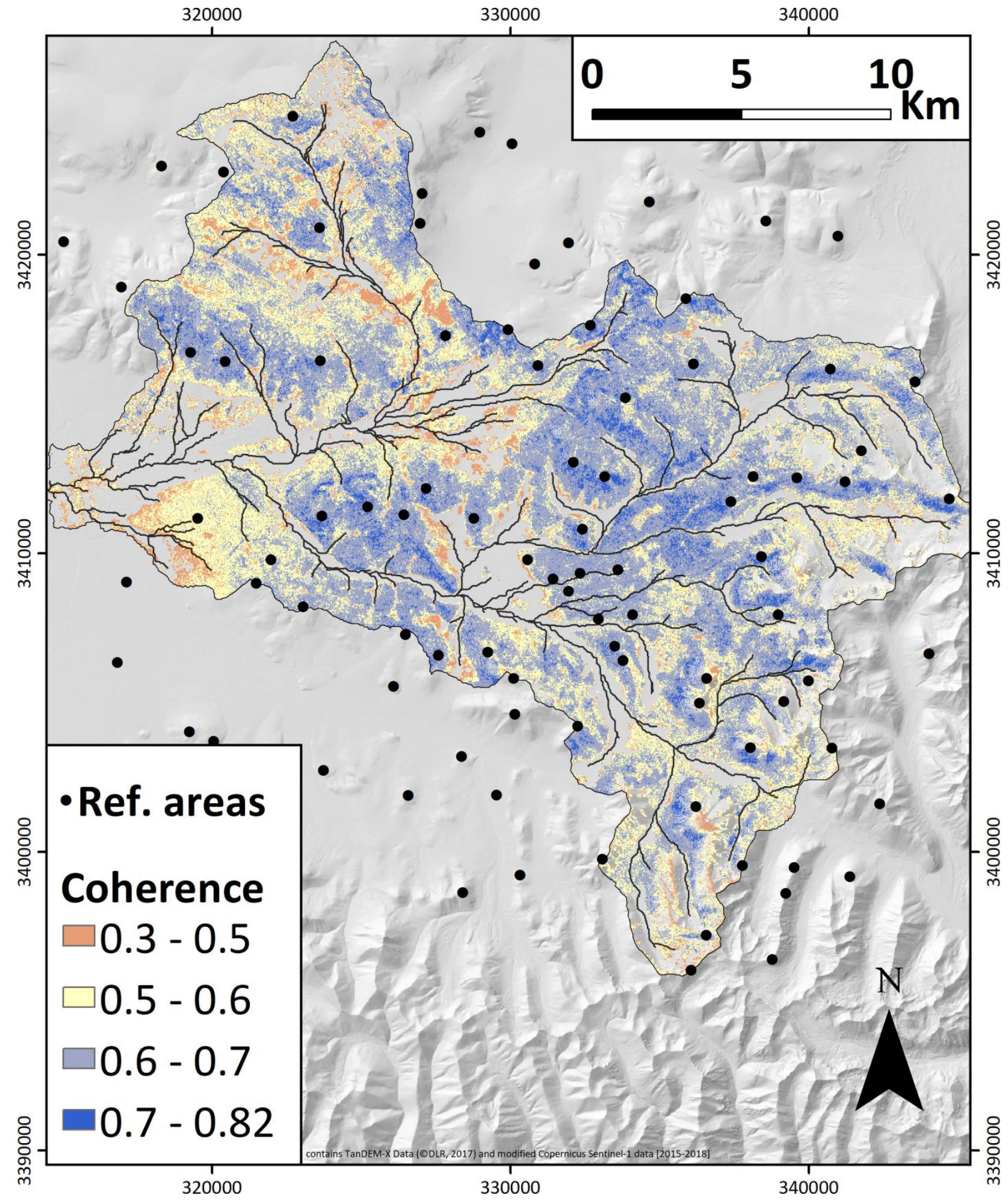

S2: Coherence map and reference areas of the ascending ISBAS processing chain of Niyaqu basin. 


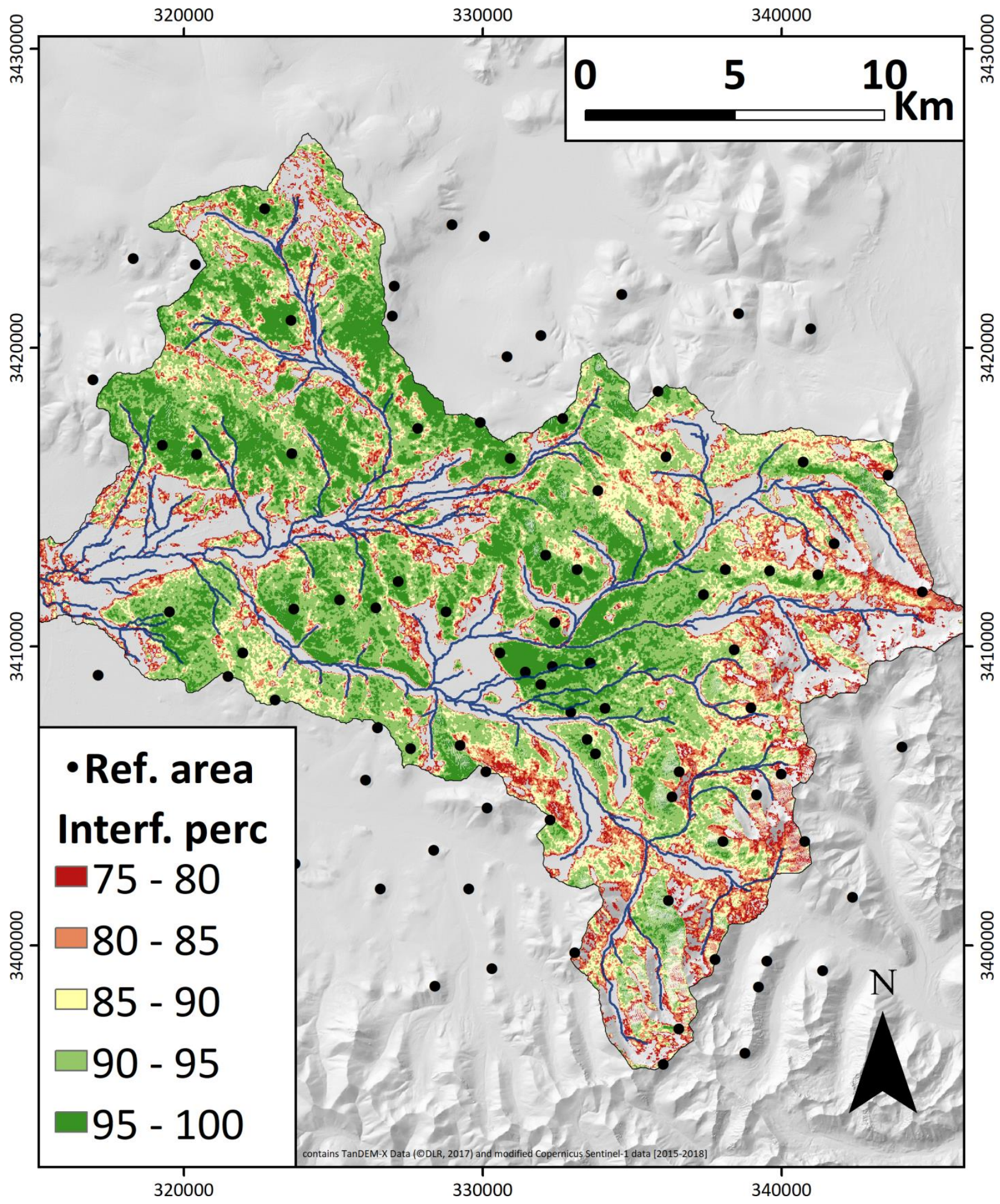

S3: Percentage of how many interferograms used for the ascending ISBAS processing chain of Niyaqu basin feature a coherence $>0.3$. 


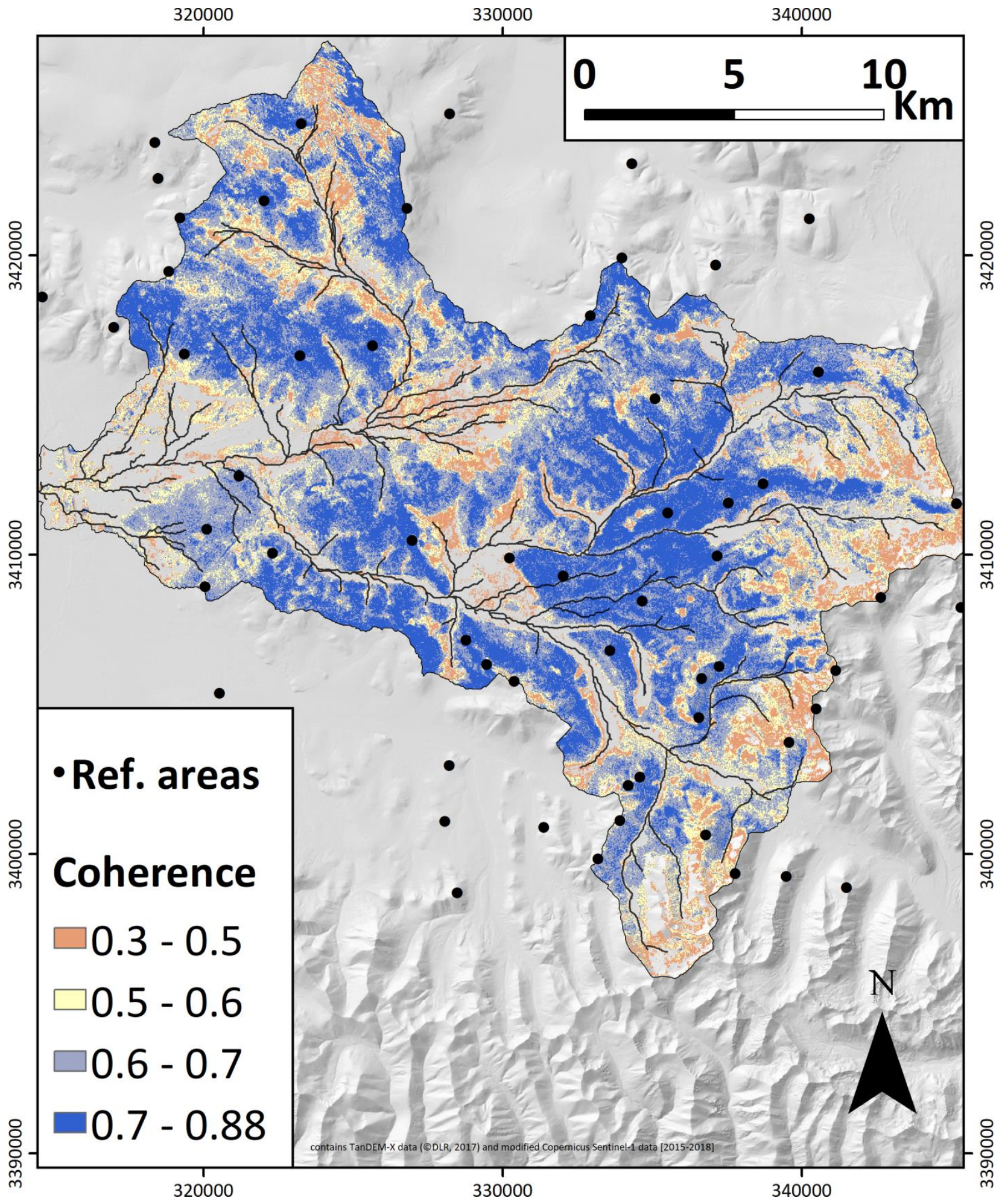

S4: Coherence map and reference areas of the descending ISBAS processing chain of Niyaqu basin. 


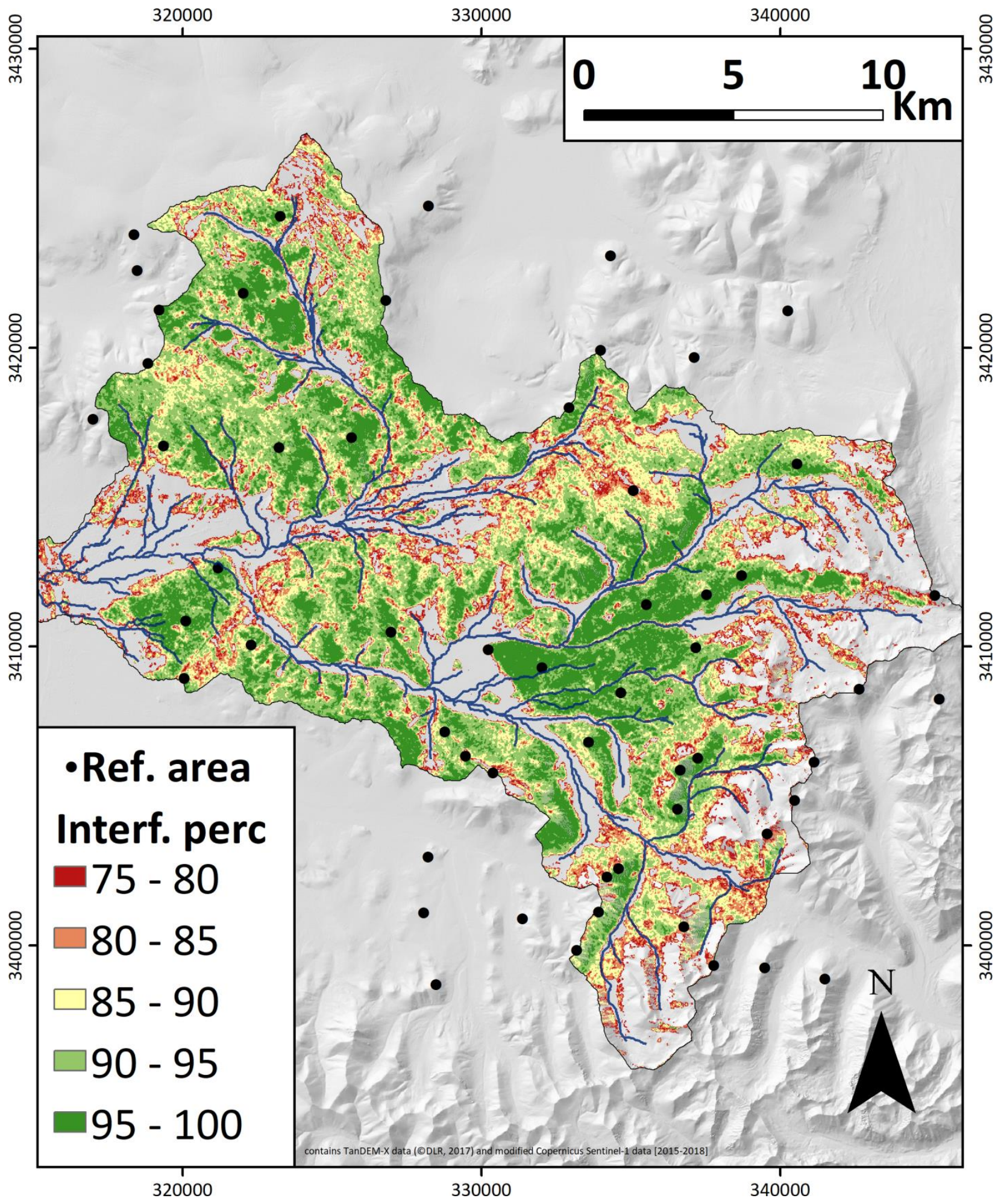

S5: Percentage of how many interferograms used for the descending ISBAS processing chain of Niyaqu basin feature a coherence $>0.3$. 


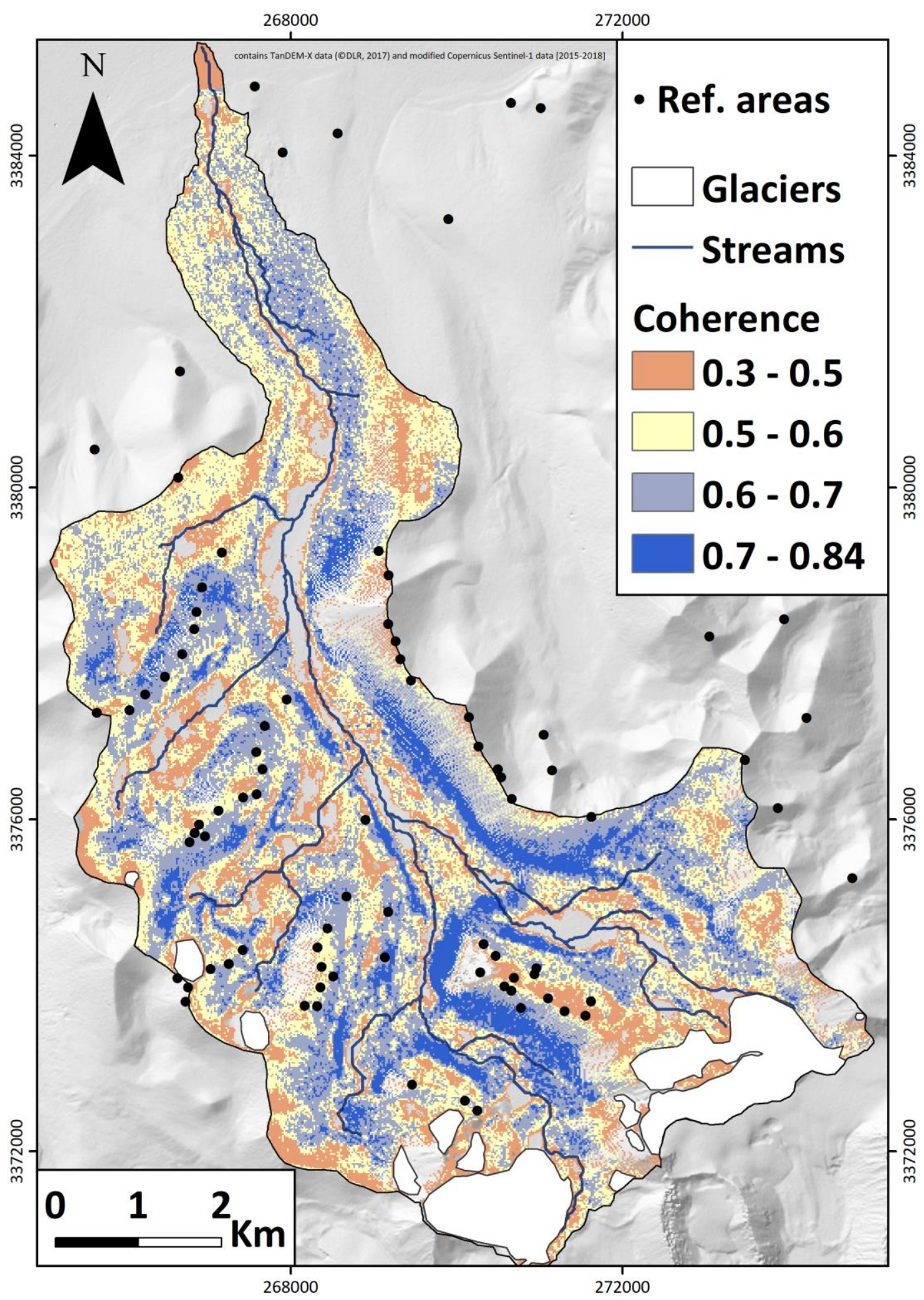

S6: Coherence map and reference areas of the ascending ISBAS processing chain of Qugaqie basin. 


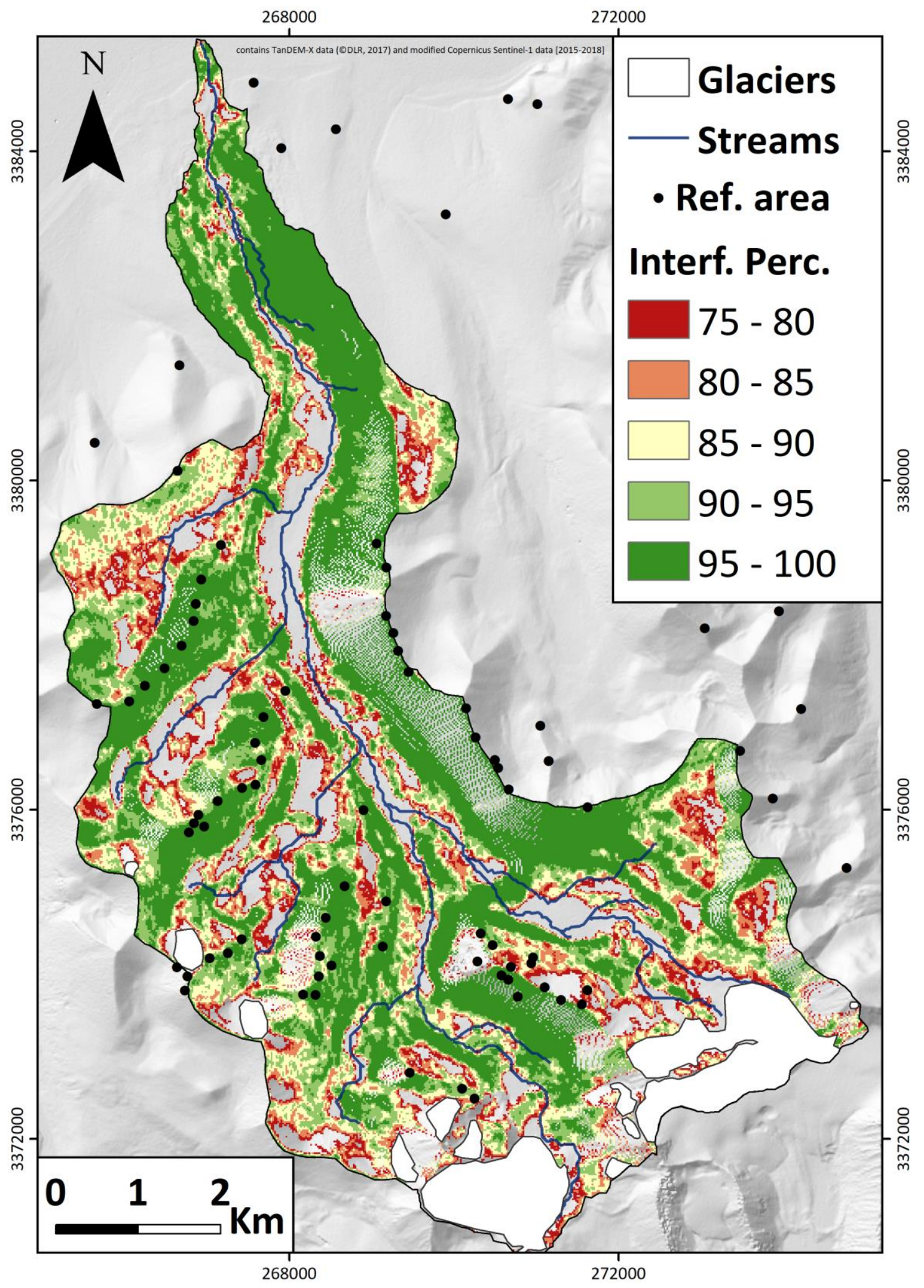

S7: Percentage of how many interferograms used for the ascending ISBAS processing chain of Qugaqie basin feature a coherence $>0.3$. 


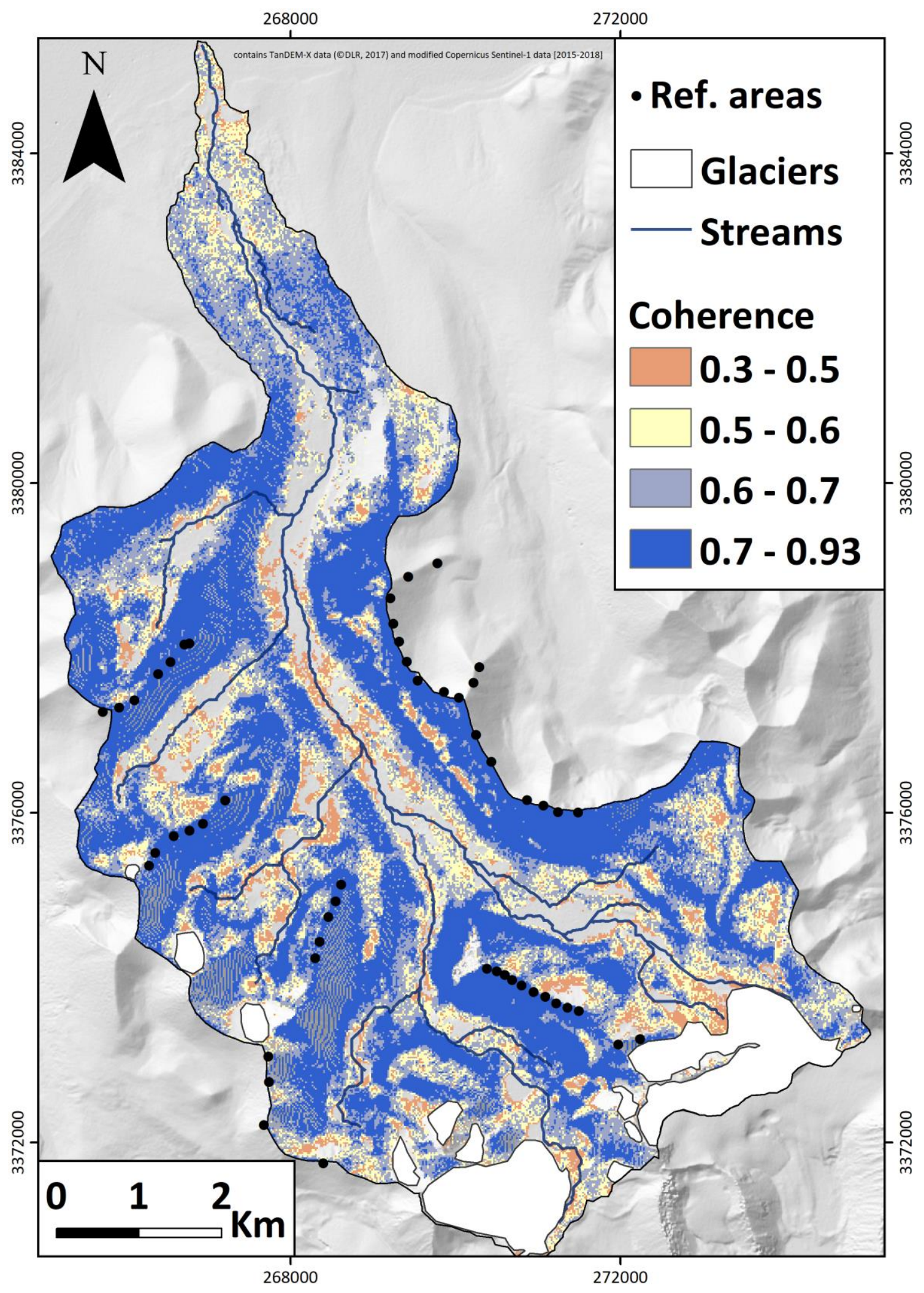

S8: Coherence map and reference areas of the descending ISBAS processing chain of Qugaqie basin. 


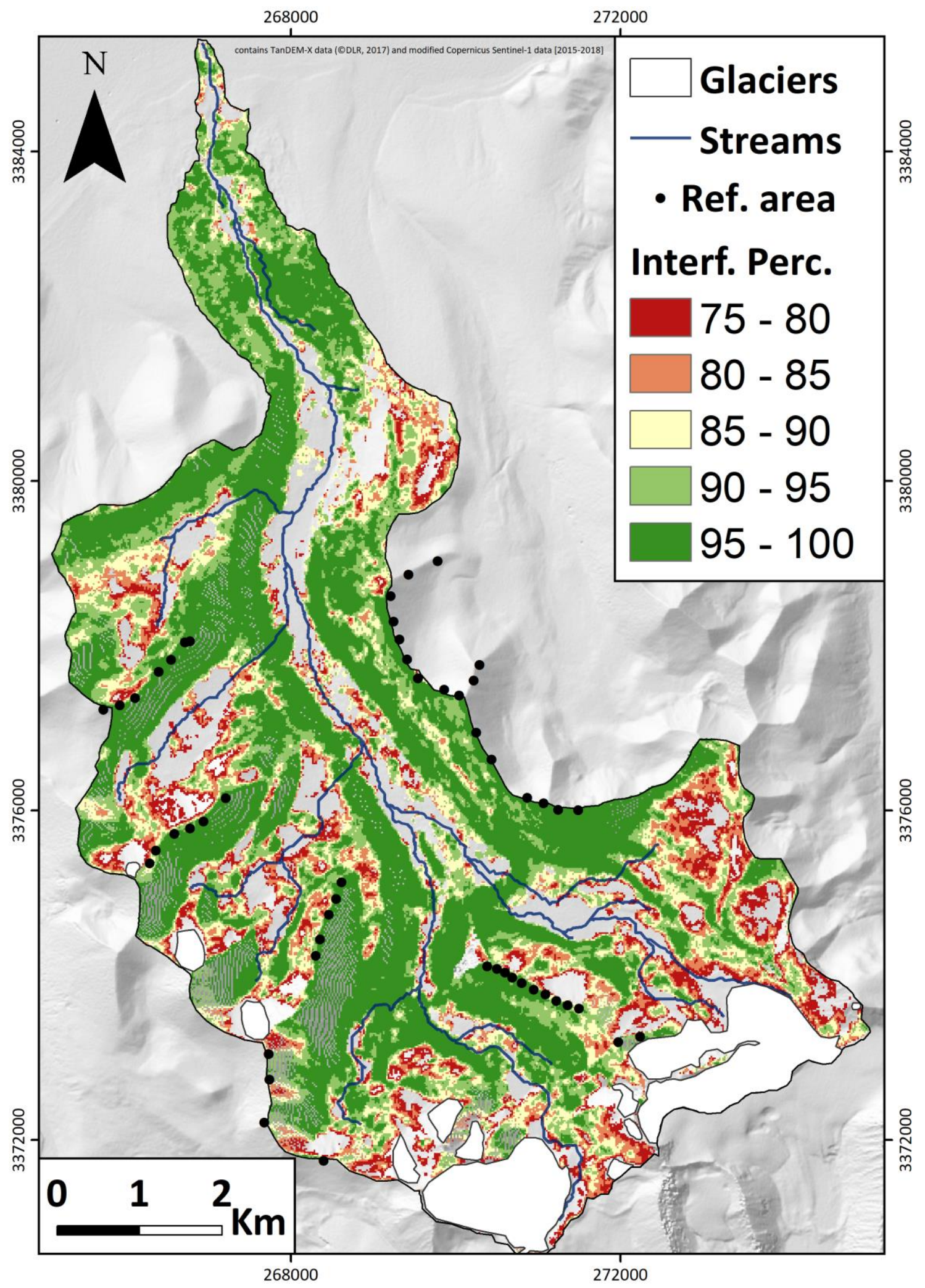

S9: Percentage of how many interferograms used for the descending ISBAS processing chain of Qugaqie basin feature a coherence $>0.3$. 


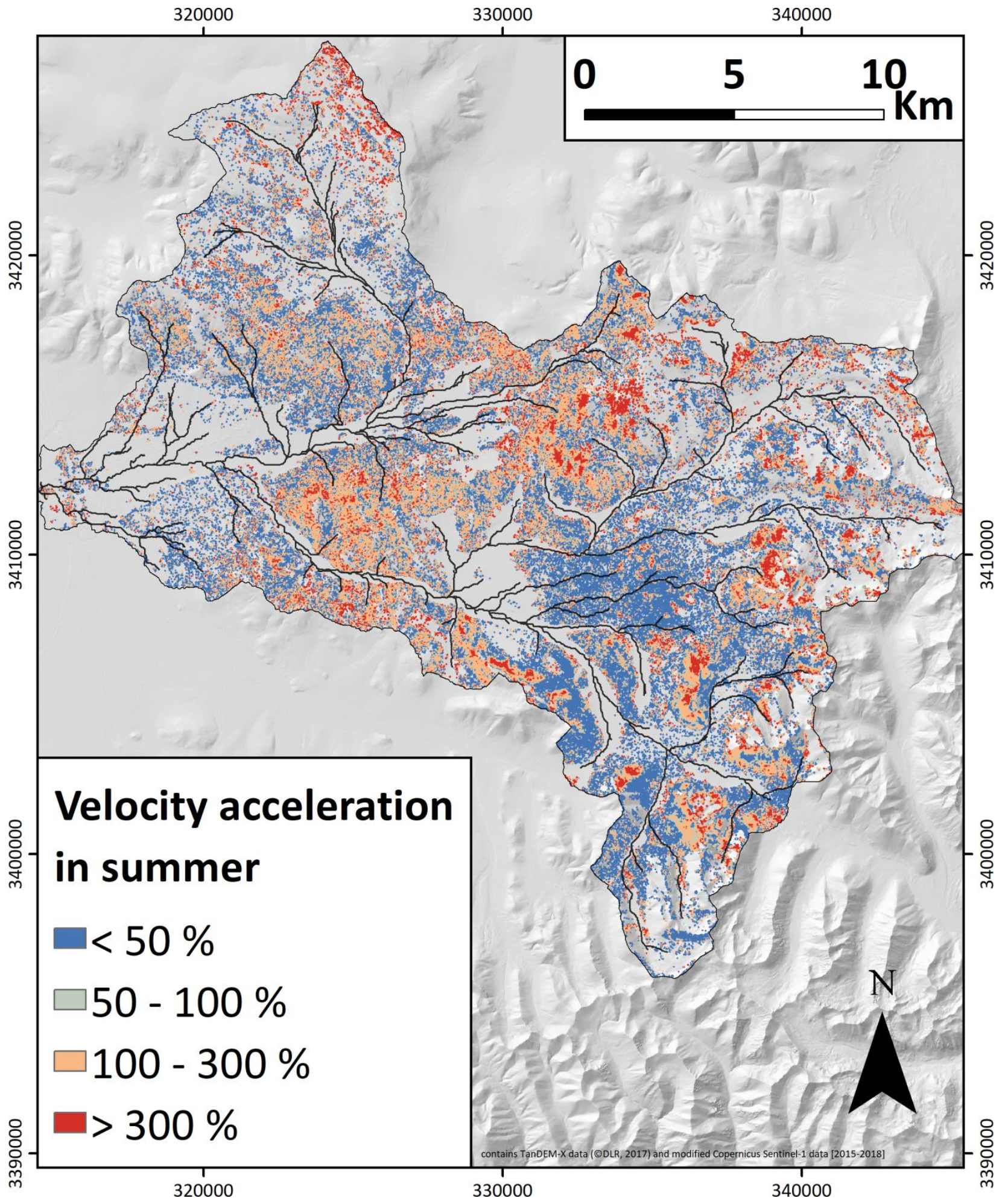

S10: Seasonal slope process model of Niyaqu basin. 


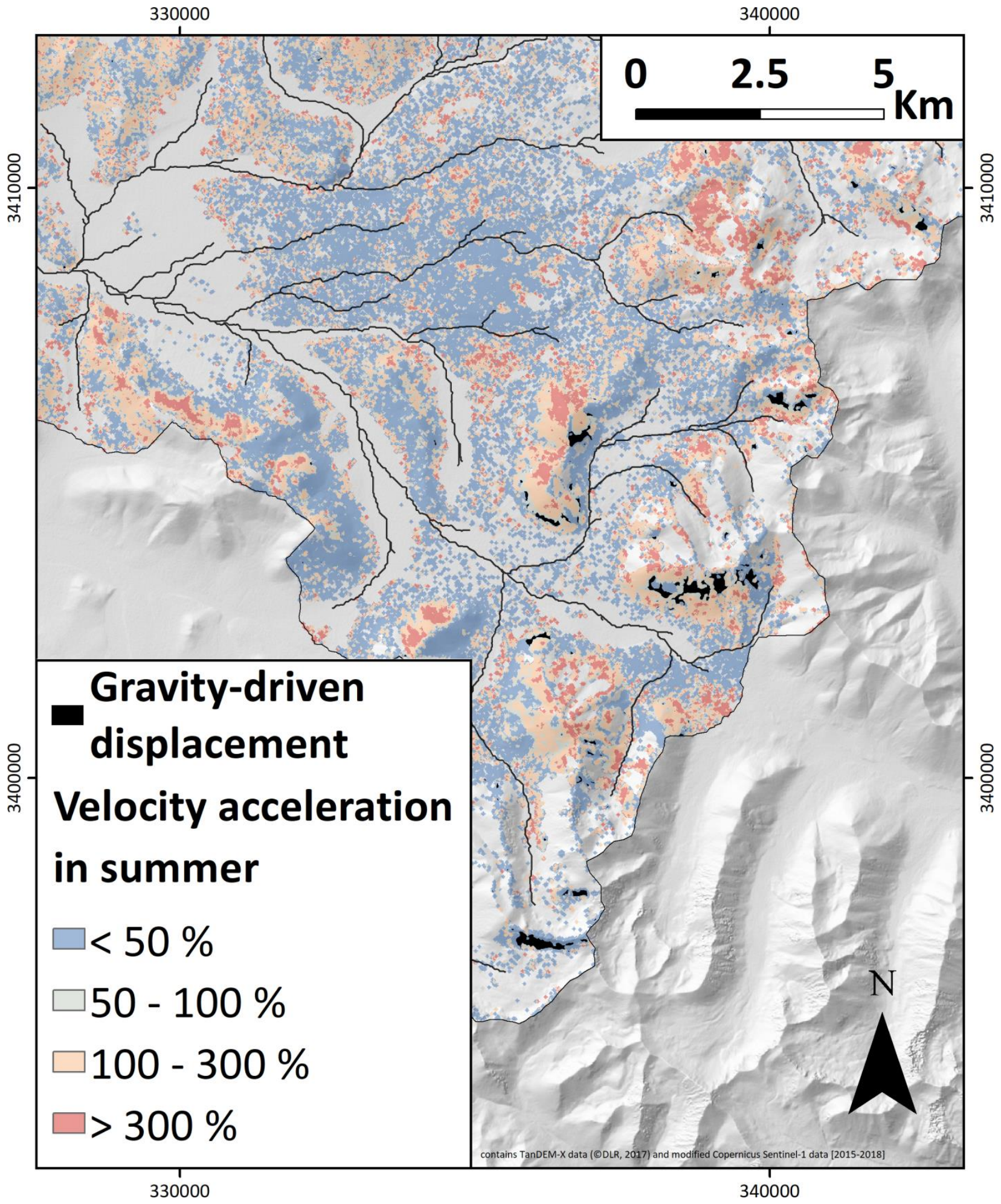

S11: Seasonal slope process model of the higher zones of Niyaqu basin highlighting areas with a high linear velocity ( $<50 \%$ velocity acceleration in summer and $>50 \mathrm{~mm} \mathrm{yr}^{-1}$ mean downslope velocity) associated with gravity-driven processes. 


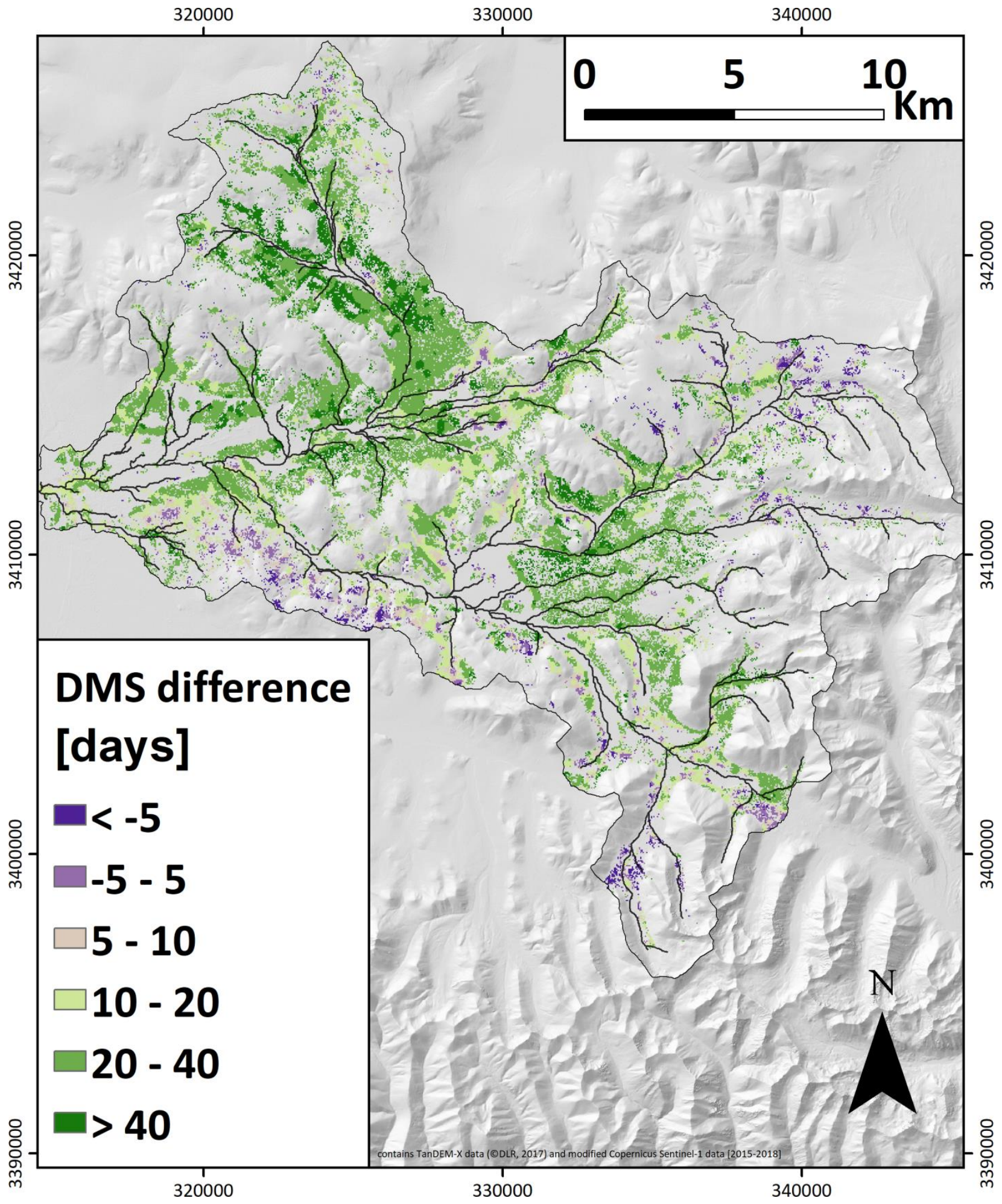

S12: Difference in the Day of Maximum subsidence (DMS) between ascending and descending data sets in the Niyaqu basin. Negative values indicate an earlier DMS in ascending data, positive values indicate an earlier DMS in descending data. 


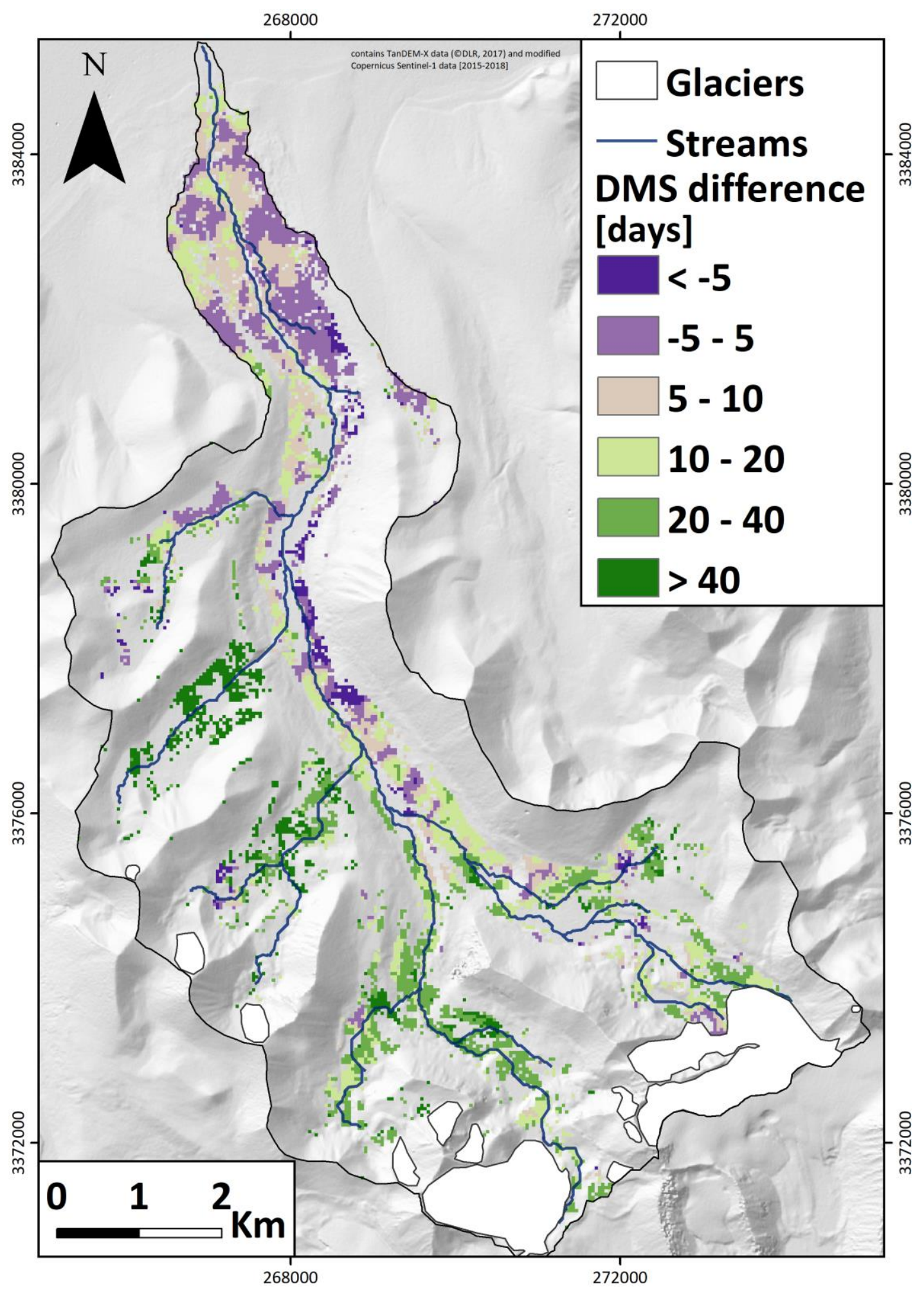

S13: Difference in the Day of Maximum subsidence (DMS) between ascending and descending data sets in the Qugaqie basin. Negative values indicate an earlier DMS in ascending data, positive values indicate an earlier DMS in descending data. 


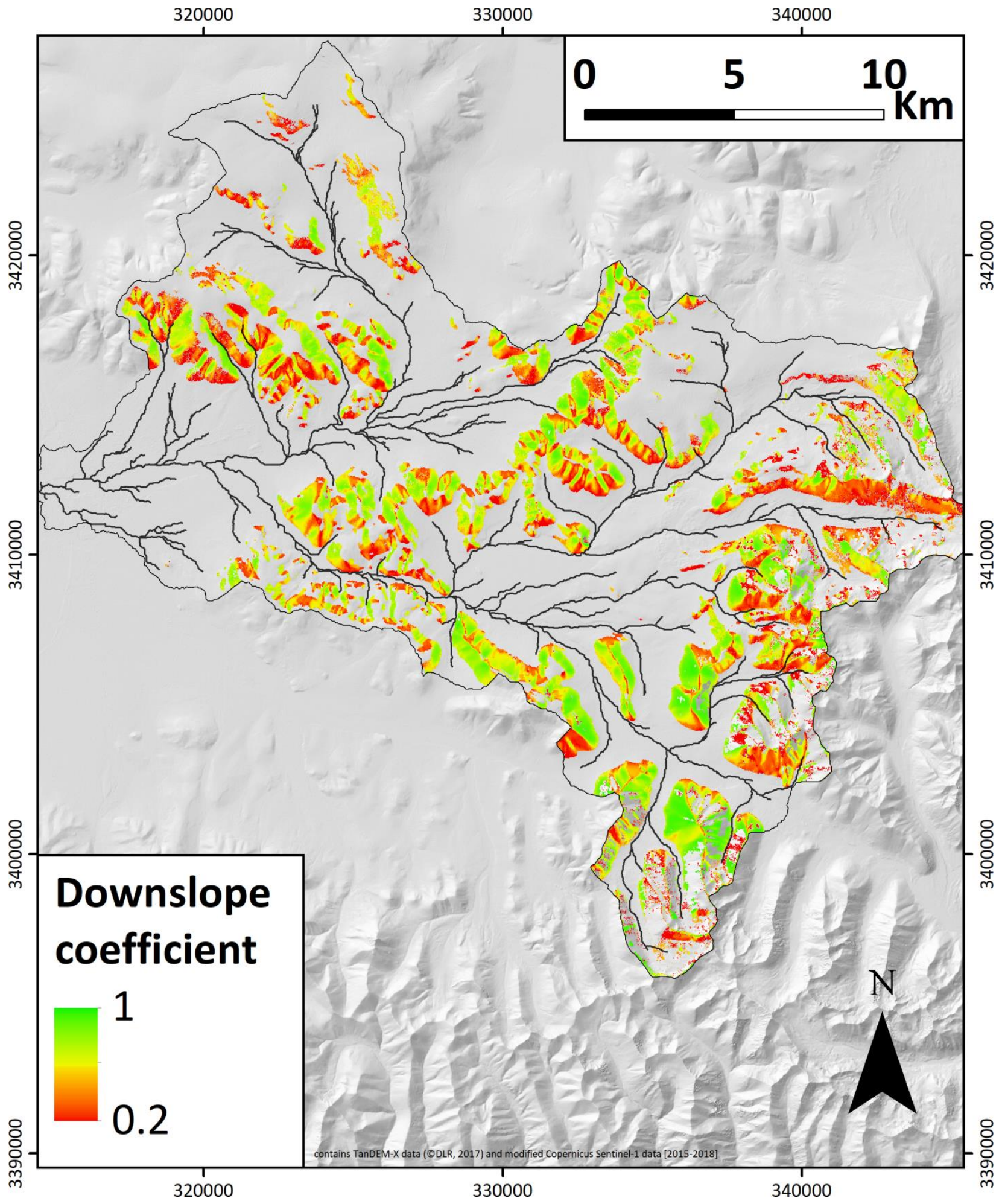

S14: Downslope coefficient calculated after Notti et al., (2014) for steep terrain of Niyaqu basin. 


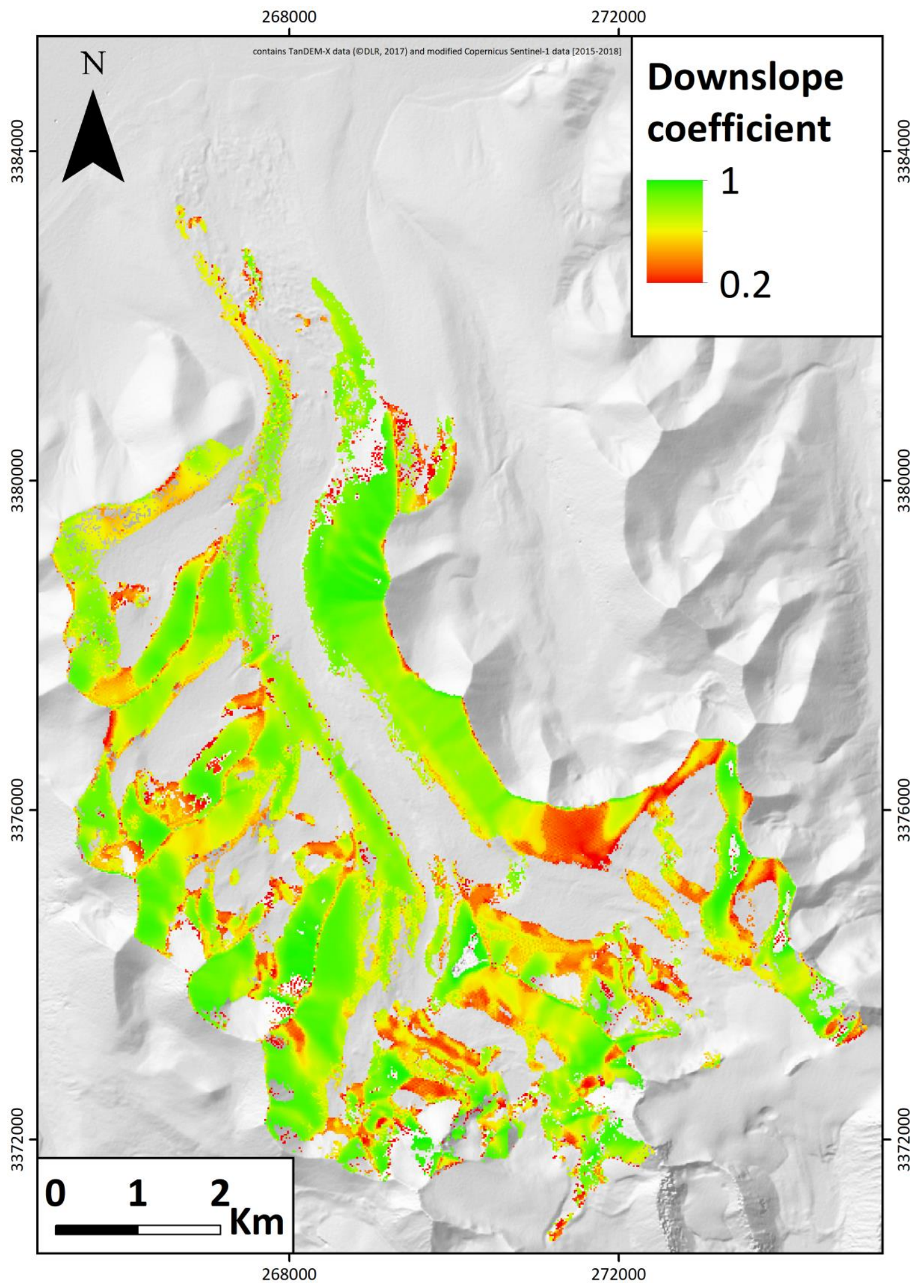

S15: Downslope coefficient calculated after Notti et al., (2014) for steep terrain of Qugaqie basin. 


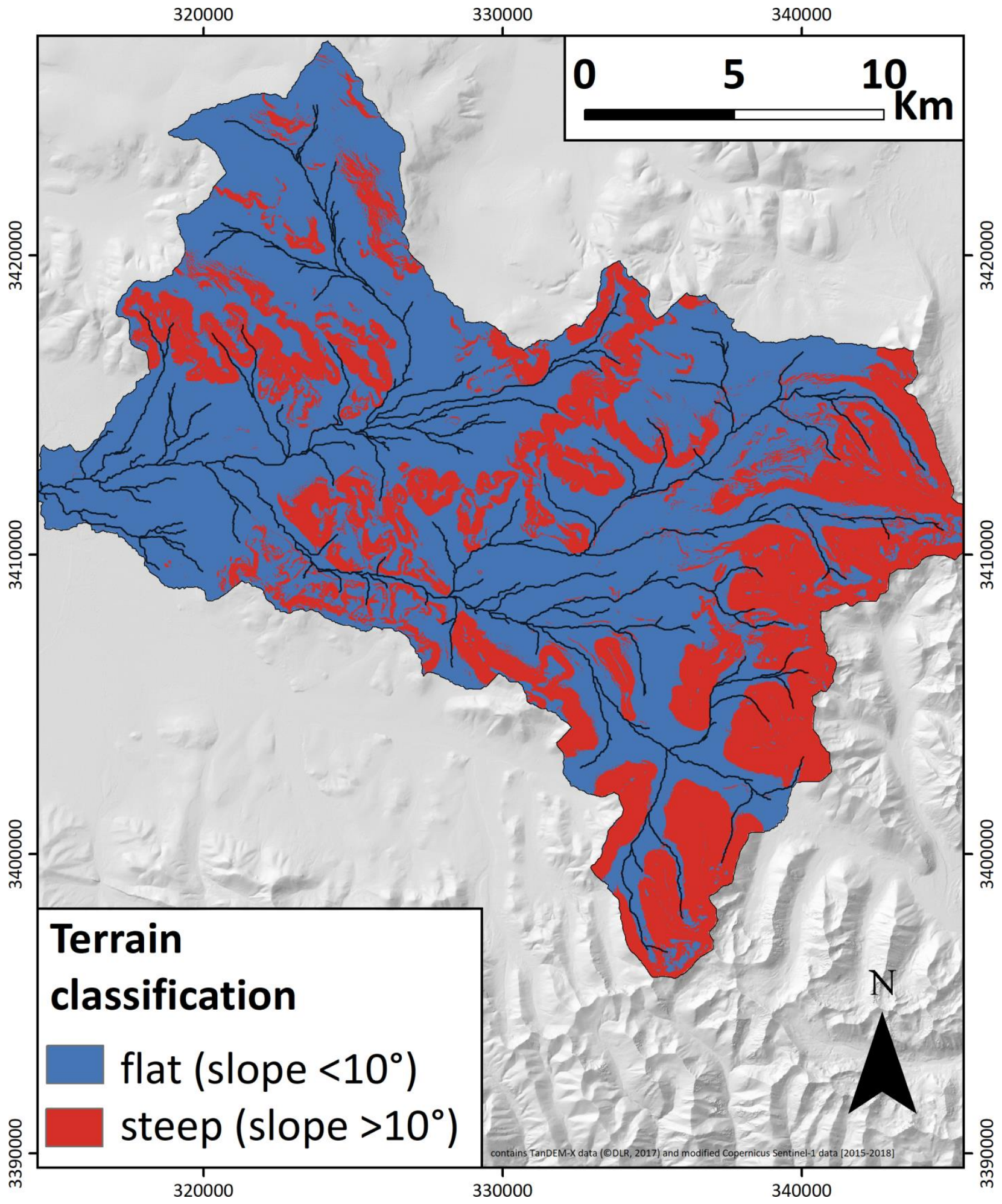

S16: Terrain classification into flat terrain $\left(\right.$ slope $<10^{\circ}$ ) and steep terrain (slope $>10^{\circ}$ ) of Niyaqu basin. 


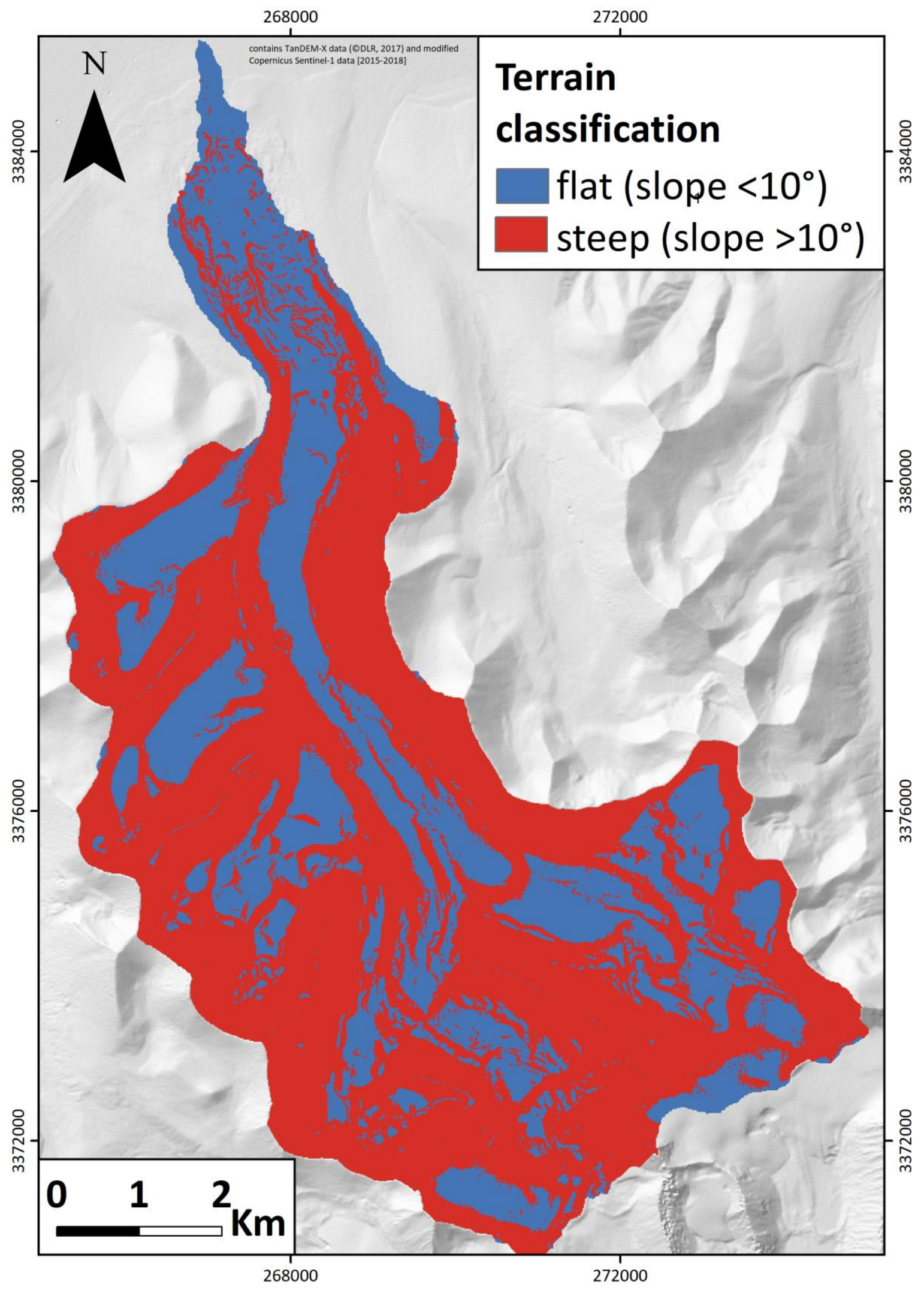

S17: Terrain classification into flat terrain $\left(\right.$ slope $<10^{\circ}$ ) and steep terrain (slope $>10^{\circ}$ ) of Niyaqu basin. 

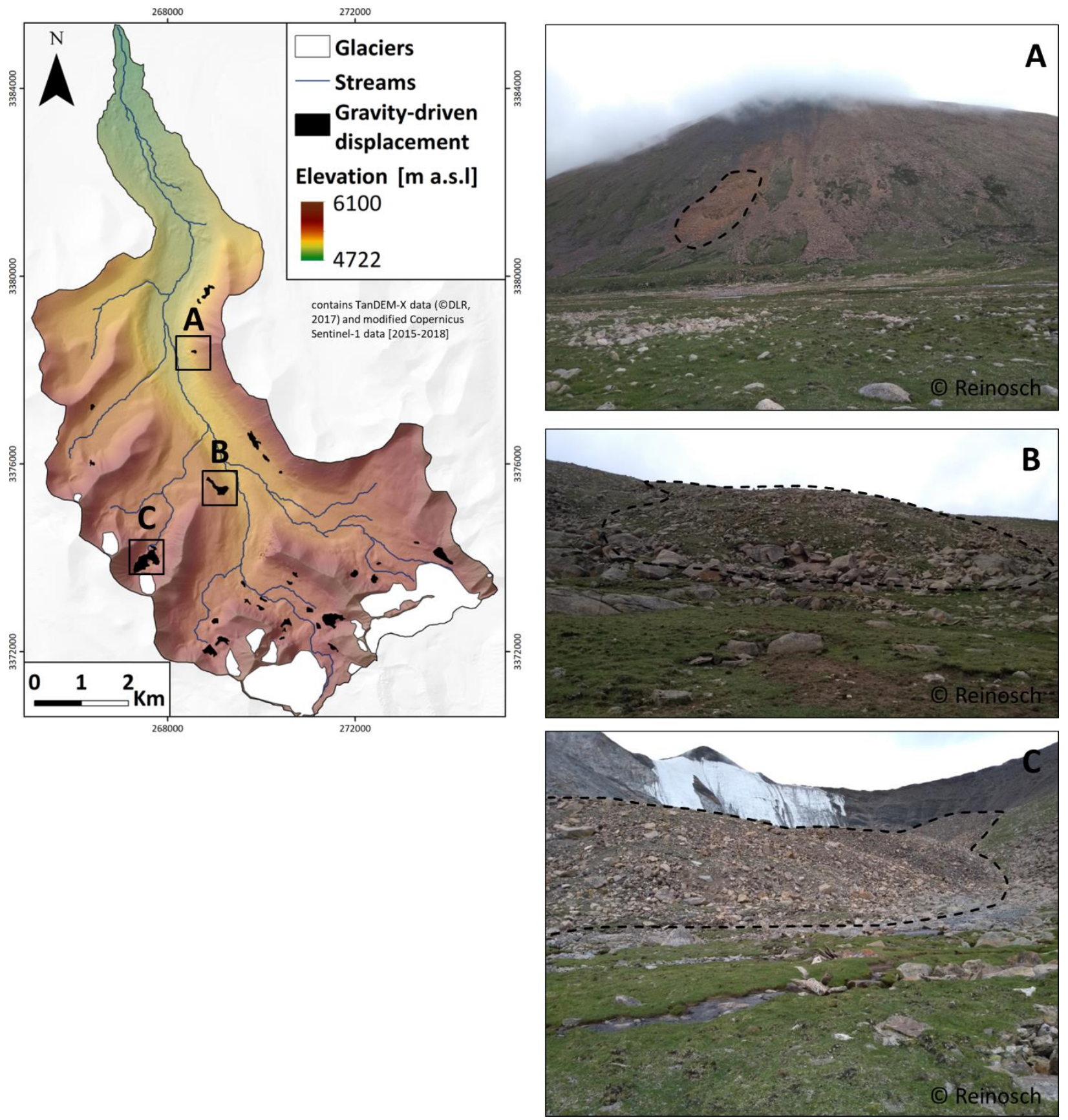

S18: Examples for the three dominant linearly moving landforms in Qugaqie basin: Rock slope instability $(A)$, frozen moraine (B) and rock glacier (C). The dotted lines outline the landforms shown in black in the overview map on the left. 